\title{
Regarding Responsibility for Land Use and Eco-systems Some Problems of Social Traps
}

\section{Hans Lenk}

Former \& Now Honorary President of the International Institute of Philosophy

\begin{abstract}
Interdisciplinary Studies and cooperations are necessary for practical work as well as studies in geodesy. Responsibility is a function of power, impact and knowledge. The more strategically central one's position is in terms of power, influence and knowledge, the higher one's responsibility is. This is an idea which can be worked out in more detail by using interdisciplinary approaches and distributive models on different levels.- Social traps, Prisoners' Dilemma situations etc. as pertaining to land, soil, and environment as well as some examples from geodesics and the study of the usage of nature systems like lakes and flood plain areas are discussed regarding responsibility and distribution problems. "Naturalists' Dilemmas" (or "Enjoyers' Dilemmas") are sketched and potentially solved by proposing a viable distribution strategy.
\end{abstract}

Keywords: Interdisciplinarity in Geosciences; Social Traps; Naturalists' Dilemma; Enjoyers' Dilemma; Distributing and Partaking

Responsibility is a function of power, impact and knowledge. The more strategically central one's position is in terms of power, influence and knowledge, the higher his responsibility would be. This is an idea which can be worked out in more detail by using distributive models of graph theory and predistribution assignments of rights and duties according to different levels. (cf., eg., The Analytic Hierarchy Process by Thomas Saaty (1980), for such a differentiation with respect to levels to employ social values in public decision-makings.)

\section{Social traps, Prisoners' Dilemma situations etc. as pertaining to land, soil, and environment}

In economics and social science scholars speak of social traps, the externalities problem, side-effects, social costs, the Prisoners' Dilemma, and the public goods problem. I would like to illustrate the problem first by using the problem structure of the so-called "Tragedy of the Commons" (Hardin 1968). This constellation can be understood as a prototype of a social trap. The central question will turn out to be: Who would bear the responsibility for an action result and for the respective consequences which nobody had wanted or intended beforehand?

According to Hardin every owner of stock in the Sahel zone has an individual and perfectly legitimate interest in utilizing and exploiting the common grassland, the so-called "commons", which is indeed a collective good. This individual interest is characterized by striving to have as many stock as possible, because the greater one's own stock, the higher is one's social status. All the owners and society in general, however, have a common interest, a real commonality, namely to avoid overgrazing of the commons. This constellation of individual and common interests would lead to the following dilemma: Because nobody has sufficient individual interest to avoid extensive exploitation of the commons for his own good, everybody will utilize it as extensively as possible; therefore overgrazing of the commons would be the necessary result and consequently in the last analysis the very satisfaction of the individual interest would be barred or ruined, respectively. Hardin thinks it necessary to have social, i.e. non-individual mechanisms of control, in order to avoid such a dilemma. Socially enforced cooperation, e.g., would be such a controlling mechanism. He emphasized that such "tragedies of the commons" would undermine or at least relativize the

EnPress Publisher LLC.This work is licensed under the Creative Commons Attribution-NonCommercial 4.0 International License (CC BY-NC 4.0). http://creativecommons.org/licenses/ by/4.0/ 
well-known traditional theorem of "the invisible hand" after Adam Smith. ("The invisible hand" in terms of the market mechanism would according to the opinion of classical and neoclassical economists result in a constellation that the consequences (profit or loss, respectively) would be attributed to the responsible agent and that an optimum overall result in terms of an optimal equilibrium and general wealth, i.e. a Pareto optimum would occur.) According to Hardin the rational maximizing of each individual interest need not, via dynamic market processes, lead to an optimum result and wealth for all. On the contrary, it may lead to depletion, erosion and pollution etc., of the common land. A similar problem with respect to arable land use also leads to depletion, erosion, even devastation of arable land in large parts of Africa: only few remaining trees and shrubs are necessarily used and/or consumed to satisfy pressing survival interests of individual families. This consumption leads to further expansion of the desert and to an additional deterioration of sustenance and survival conditions of the whole population etc. (With respect to stock and the above-mentioned traditional conflict between the individual owners' interests and social needs even the boring of additional wells might even aggravate or escalate the conflict constellation and accelerate the ecological problems. This might be a well-known unintended side-effect of political and economical development programmes.)

A similar effect is the clearing and making arable of tropical rain forests on basically poor soil which might lead to local and regional erosion and depletion of the ecosystem and to a continental or even global change of the climate (cf. the global carbon dioxide problem and the impending glass house effect of overheating the atmosphere).

According to Hardin the problem of environmental pollution turns out to be of analogical or equivalent structure. The commons, a public good in this case, however, is not diminishing or decreasing in size, but instead a negative quality is added, namely through the depositing of refuse of many kinds. Again, it is profitable, i.e. cheaper, for the agent to do away with garbage on public soil, e.g., to deposit chemical refuse in the Rhine. As a consequence of these public measures external social costs would result. Negative external effects which would amount to a burden for the general society; they can only be avoided or redirected if the taxpayer or everybody pays in money or is suffering in terms of health disadvantages, deterioration of quality of life or aesthetic qualities of ecosystems and the landscape. Externalities would result from the actions of producers and consumers whenever these agree on actions which would be disadvantageous for the environment (think of the example of the one-way bottles). Therefore, there is also a responsibility of consumers, a co- or joint responsibility with respect to the protection of the environment. On different levels of a scaling phenomenon all members of a society would bear a certain responsibility for an acceptable or good and healthy state of their respective society (Kerber 1988, 243).

Generally speaking the same structure is to be found with many problems of social constellations which can be dubbed social trap constellations. It would be profitable for individuals to infringe social rules and norms as long as (almost) all other members are abiding by them. A similar structure is to be found in the so-called Free-Rider Problem and the assurance problem with respect to providing and maintaining collective and public goods. Both cases lead to social traps. The dilemma of environmental protection on a voluntary basis is an intriguing example of this constellation. The free-rider problem is "A barrier to successful collective action or to the production of a public good that arises because all or some individuals attempt to take a free ride on the contribution of others. Non-contributors (would) reason as follows: Either enough others will contribute to achieve the good or they will not, regardless of whether I contribute or not; but if the good is achieved, I will benefit from it even if I don't contribute. Consequently, since contributing is a cost, I should not contribute" (Buchanan 1985, 124). The assurance problem is "a barrier to successful collective action or to the production of a public good that arises when all or some individuals decide not to contribute to the good in question because they lack adequate assurance that enough others will contribute" (ibd.). The provision and maintenance of a collective good is according to Olson (1968) primarily dependent on the magnitude of group membership: The greater a group of participating individuals, the less the chance and opportunity turn out to be for providing and maintaining such a good and the greater is the necessity of compulsion, sanctions etc. with respect to usage and distribution of collective goods. Whereas community norms or a morale would still seem satisfactory for reaching a common goal in small groups, this does not apply to large groups. (Buchanan called this phenomenon "the 
large number dilemma" (Vanberg 1982, 137).)

The structural problems of social and individual actions, of public goods, and of the commons and social order can easily be illustrated by using the well-known game theoretical model of the so-called Prisoners' Dilemma (PD). A detailed analysis of the PD structure shows that strategic actions of competing self-interested rational agents lead to a result which turns out to be an unintended social consequence putting all participants on a worse level than a cooperative strategy of abiding by social rules would have obtained. PD-constellations cannot be solved on a pure individualistic level.

The above-mentioned dilemmas are also examples of rationality traps: the individually rational action strategy leads to collective social irrationality undermining the first one. Under certain conditions, individual rationality can be self-destructive.

The second problem of distributing responsibility does not result from collective corporate action by itself, but only if many act under strategic (competitive) conditions, if negative external, synergistic and/or cumulative effects occur. Indeed, "strategic conditions" means that the final result is dependent on the (relatively independent) acting of many individual agents. Synergistic and cumulative effects would only result, if different components have a joint and mutually escalating impact; the individual components might by themselves be (relatively) harmless, i.e. remain under a certain threshoId-value, but result in the deterioration or even loss of a highly valued common good (think of the example of the continental European forest "dying" from pollution by acid rain and erosion).

\section{Extended responsibility and eco-liability}

The distribution problem of responsibility consists in the fact that side-effects cannot be attributed to a single originator and that they usually were/are or even could not be foreseen or predicted. We have two partial problems here: First the question of participatory responsibility with respect to cumulative and synergistic harmful effects and second the question how to responsibly deal with unforeseen or even unpredictable facts or side-effects. The first problem can be called the problem of distributing responsibility under strategic conditions. For instance, is the legal principle of attributing "causality" and responsibility valid in Japan since the case of the Minamata disease according to which the statistically assessed contribution to the common harm by relevant polluters in the vicinity is ascertained, by law, as the pertaining causality indeed satisfactory? The burden of proof here lies so to speak on the side of the potential originator, the polluter, who has to prove the harmlessness of his emissions. This reversal of the burden of proof seems to be at least a controllable and operational measure to allow for attribution wherever environmental damages are in question. In these detriments usually land, water and air use or misuse are combined. They can at least be tendentially forestalled or diminished in a controllable way by assigning sanctions. In that respect the Japanese legal principle of attributing causality might foster environmental protection. But there are methodological and legal as well as moral problems connected with such a regulation. First of all, adjacency and the guessing of causality can never be a proof of a causal origin. In addition, the problem is how to attribute distributively the responsibility in the cases of synergistic and cumulative damages, particularly those with below-threshold-contributions of individual agents. Another problem is how to distinguish between a descriptive assessment of causal origination and the normative attribution of responsibility, between causal responsibility and liability after Hart (1968). How could one possibly distinguish between the causal impact, the descriptive responsibility, i.e. the descriptive attribution of responsibility, and the respective normative attribution of responsibility for contributions - the amount of which is individually ineffective, below the threshold of harmfulness? And how is one to distribute this kind of responsibility in general? Would it not be meaningful to postulate a normative collective responsibility of all pertinent corporations within the respective region in the sense of a joint liability? This would, however, mean a liability of all relevant corporations for the total damages. The impaired parties could sue for damages, claim in court for compensation and/or indemnification from any presumably participating corporation. Does this make sense, if connected with an overall generalization? This regulation, however, would have the advantage of dispensing with the proof of damage in respect of each singular damaging or aggrieving party - as e.g. a respective norm in German Civil law would prescribe. This kind of regulation 
would, in some way independent of individual case argumentation, interpret all non-collective agents as quasi one corporative agent being liable in total. The internal distribution and compensation within this quasi-group of corporate agents would then be a problem of mutual bargaining of all aggrieving parties.

Notwithstanding these arguments another kind of total liability with respect to product safety and hazards in terms of environmental damages of public goods should be established. It should be noted that there is a European Community agreement as of 1985 with regard to product liability laws. Causal originators of damages would then/now be liable in the sense of a strict liability in tort, whether or not they are really guilty in terms of intent or only negligent. Causal origination would already ascertain descriptive causal action responsibility and with respect to the damage of a good to be protected also normative responsibility for the respective action and its consequences. This form of liability would hopefully be deterrent enough to prevent infringements. If, however, damages would nevertheless occur it would at least not be necessary to prove fault or guiltiness as a presupposition of any claim for compensation.

Is man because of his immense power of technical encroachment and feasibility beyond any beforehand imagination and control responsible for much more, so to speak, than he could possibly foresee and literally (intentionally) be normatively responsible for? Should he not take over responsibility for unforeseen or even unforseeable side-effects of his actions with respect to technological and scientific big science projects? But how could he possibly do that? There is no way of really morally being held responsible for something one does not know or could not know. In the sense of causal responsibility (descriptive origination) one can be held responsible in some sense, if an unintended damage occurs; the question however is, whether one could be held responsible too in a normative-moral sense. The so-called principle of causation if interpreted in a moral and legal sense, would - at least in tendency adequately design normative responsibility also. One would have to answer for, to make good and to be liable for consequences in the sense of being liable to pay compensation etc. The range and power of action seems to have multiplied to such a degree that anticipation cannot follow quickly enough or pursue all the complex ramifications of impacts, consequences and side-effects. This seems to be an intriguing dilemma of responsibility in our systems technological age impregnated by complex systems interactions and dynamic changes easily transgressing linear thinking and traditional causal disciplinary knowledge. In principle this also pertains to eco-systems and their respective land bases.

Earlier (1998, 439f), I dubbed the distribution dilemma regarding the using or enjoying a nature resource or eco-system by different users (e.g. fishermen and anglers, hobby sailors, rowers, swimmers, naturalists etc. taking advantage of a lake) "the Naturalists' Dilemma". By contradistinction to the PD, this situation can be pragmatically tackled and the problems solved by delimitating, dividing and distributing spaces and/or times, certainly e.g., by mutual agreement.

Technology, technological progress and economic-industrial development in combination with the respective damages for land, clean air and water turn out to be multi-dimensional phenomena asking for interdisciplinary and complex approaches. The multi-perspectivity is the result of a mutual ongoing interaction between diverse realms and actions of many corporate and individual agents. This is leading to a rather great complexity of individual, collective and corporate contributions, different areas and social background factors. The exponential structure of technological development in terms of range, energy, acceleration, interaction feedback phenomena etc. is a familiar insight of traditional sociology of science, technology and economic development. This insight is generally true for any multi-ramified and inter-disciplinarily interlocked social phenomenon of development.

With regard to responsibility in general, it is not only corporations and institutions in economics and industry which have to bear responsibility, but also the state and its representative decision makers. Corporate responsibility has to be connected with individual responsibilities of the respective representative decision makers. This is true also for big technology projects, particularly if they are run by the state itself. There should be not only a legal, but also a moral balance of powers in terms of checks and controls similar to the traditional distribution of power between legislature, government and jurisdiction. 


\section{Conclusion}

The extension of individualistic responsibility is to be combined with the development of a socially proportionate co-responsibility, and with the establishment and analytic as well as institutional elaboration of corporate responsibility and a new sensitivity of moral conscience. Types of responsibility have to be analyzed in a more differentiated way than hitherto. Only in this way we may be able to cope with the most complex structures of causal networks and the far-ranging consequences of human actions and social impacts. Concepts for a more social orientation of responsibility and conscience should be given most attention. Ethics and moral philosophy have to take these new systemic challenges by technically multiplied possibilities and impacts of action and system networks. An applied ethics of not only collective, but also of strategic and network actions as well as their consequences would seem to be urgently needed indeed.

\section{References}

1. Buchanan A. Ethics, efficiency, and the market. Totowa NJ, 1985.

2. French PA. Collective and corporative responsibility. New York, 1984.

3. Hardin G. The Tradegy of the commons, in science 162 (1968), 1243-1248.

4. Hart HLA. Punishment and responsibility. Oxford, 1968.

5. Kerber W. Sittlich handeln unter dem Zwang ökonomischer Sachzwänge, in Hesse, H. (Ed.): Wirtschaftswissenschaft und Ethik. Berlin 1988; 241-258.

6. Lenk H. Zur Sozialphilosophie der Technik. Frankfurt, 1982.

7. Lenk H. Verantwortung für die Natur, in Allgemeine Zeitschrift für Philosophie 8 (1983), 1-18.

8. Lenk H. Konkrete Humanität. Frankfurt/M. 1998.

9. Lenk H, Maring M, Natur - Umwelt - Ethik. Münster, 2003.

10. Lenk H, Ropohl G. (Eds.) (1987): Ethik und Technik. Stuttgart, 1987, 19932.

11. Olson M. Die Logik des kollektiven Handelns. Tübingen 1968.

12. Saaty ThL. The analytic hierarchy process: planning, priority Setting, resource allocation. New York u.a. 1980.

13. Sen A. On ethics and economics. Oxford, 1987.

14. Vanberg V. Markt und Organisation. Tübingen, 1982. 